\title{
Determination of Lateral Ventricle and Brain Volume in Children with Stereological Method Using MRI
}

\author{
Determinación del Volumen del Ventrículo Lateral y del Cerebro \\ en Niños Utilizando el Método Estereológico Mediante RNM
}

\author{
Keziban Karacan*; Mehmet Ilkay Kosar*; Mehmet Çimen*; \\ Orhan Solak $^{* *}$ \& Bünyamin Sahin***
}

KARACAN, K.; KOSAR, M. I.; ÇIMEN, M.; SOLAK, O. \& SAHIN, B. Determination of lateral ventricle and brain volume in Children with stereological method using MRI. Int. J. Morphol., 31(1):211-216, 2013.

SUMMARY: Although brain development is most active during the intrauterina period of life, the processes of myelination and arborization affect the structure of the brain throughout childhood and adolescence. Brain development is also very active in the early years of a child's life, and continues to be so for approximately 15 years after gestation. Volumetric changes in the brain are effected by sex. Understanding the variability of human brain volume during development is important for the interpretation of childhood neuroimaging studies. Hence the aim of this study is to determine the effects of sex difference on brain volume (BV), lateral ventricle volume (LV) and the ratio of brain volume and lateral ventricle volumes as a percentage (RLBV\%) of 90 healthy children between the ages of 6-17 according to their sex with MRI. These children were divided into three age groups of 6-9, 10-13 and 14-17 also BV, LV were calculated using the Cavalieri principle, which is classified as a stereological method and than RLBV\% were calculated.

Results: The BV of age group 6-9 was significantly smaller than the other two age groups $(\mathrm{P}<0.05)$. General average BV of the age group 10-13 was higher than the other two age groups but this difference is insignificant. When the groups were compared according to sex, there was no important difference between girls and boys $(\mathrm{P}>0.05)$. General average LV of the age group 6-9 was higher than the other two age groups but this difference insignificant. Moreover there was no sex difference. This study was presented that BV was continued to increase until the ages 10-13 for both of the genders. While LV was increased until the ages 10-13 for boys, it was had a negative relationship with changes of BV for girls.

KEY WORDS: Brain; Lateral ventricles; Magnetic resonance imaging; Stereology.

\section{INTRODUCTION}

Even during the process of a normal pregnancy, brain development is not completed at the time of birth (Ballesteros et al., 1993). The brain reaches $75 \%$ of its adult BV at 2 years, but changes of brain structure and physiology last a life time (Giedd et al., 1996). BV in a child reaches $80 \%$ of the adult brain size by age 3 years. The brain is $\% 95$ volume of the adult brain by age 9 years. The brain completes the final $5 \%$ of its adult volume over a period 1 of time which is nearly as long as the time required for the initial $95 \%$ of volumetric acquisition (Caviness et al., 1996; Giedd et al., 2010). There is a correlation between brain volume and particular medical conditions for both children and adults. For example, studies of various diseases emphasized brain volume changes in autism, hyperactivity disorder, schizophrenia, multiple sclerosis, epilepsy, premature birth, fragile $\mathrm{X}$ syndrome, Tourettes syndrome, and Alzheimer's. At the same time the lateral ventricle volume (LV) is affected by changes in BV. Studies emphasize a negative relationship between changes of BV and LV (Creasey et al., 1986; Lawson et al., 2000; Castellanos et al., 2002; Wang et al., 2002; Thune et al., 2003; Kesler et al., 2004).

Brain imaging techniques are continually developing and the importance of brain imaging techniques in the field of child and adolescent psychiatry is increasing (Levene et al., 1982; Sten et al., 1997; Sowell et al., 2007). Use of MRI is extremely safe and effective method for use in studies of child brain development because it does not have ionizing radiation (11-13). Therefore, the purpose of this study was to calculate $\mathrm{BV}, \mathrm{LV}$ and brain/lateral ventricle volumes ratio (RLBV\%), using MRI with stereological methods in children age between 6-17 years.

* Department of Anatomy, Cumhuriyet University, Faculty of Medicine,Sivas, Turkey

** Department of Radiology, Cumhuriyet University, Faculty of Medicine, Sivas, Turkey

**** Department of Anatomy, Ondokuz Mayıs University, Faculty of Medicine,Samsun, Turkey 


\section{MATERIAL AND METHOD}

MRI was used to examine the relationship between age and sex difference with BV, LV and RLBV\% in 90 healthy children and adolescents ( 50 girls and 40 boys), age 6-17 years. Subjects were selected from children undergoing health screening of the brain at the Cumhuriyet University Faculty of Medicine Research and Application Hospital Radiology Department between March 2007 and April 2008. Participants were normal volunteers and the official permissions were taken from the university. The research was performed according to the World Medical Association Declaration of Helsinki. Subjects were divided into there age groups of 6-9 (girls:11 boys:19), 10-13(girls:21 boys:9) and 14-17(girls: 18 boys:12)by taking into consideration the sex differences.

Only subjects who met all of the following conditions were used in this study: 1) subjects had no previous brain disease; 2) no signal abnormality and cerebral tumors, infarction or hemorrhage were found on MRI; 3) no history of prenatal confounds that may influence brain maturation, such as prenatal exposure to substances or pregnancy and birth complications; 4) no positive trauma or maltreatment history; 5) no significant medical, neurological or psychiatric disorder or history of head injury or loss of consciousness. The radiologicaly evaluation was performed using a standard head coil with a 2001 model 1.5-T MRI machine (Exelart, Toshiba, Tokyo, Japonya). All of the patients images were obtained through the T2 weighted fast spin echo technique and with the following parameters: time to repeat TR=5000 ms; time to echo TE=94 ms; Flip angle $(\mathrm{FA})=90 / 160 ; \mathrm{NEX}=2$; field of view $\mathrm{FOV}=180 \times 220 \mathrm{~mm}$; matrix $=224 \times 320$ and section thickness $=6.2 \mathrm{~mm}$.

Stereological volume measurements were based on the Cavalier principle. According to the rule of this principle, sections were taken equidistant, parallel and serial for the most accurate calculations of the volume of interest (1415). Related fields in the MRI which were taken at an equal distance of $6,2 \mathrm{~mm}$ and axial $\mathrm{T} 2$ sequence were measured using a $1 / 16$ scale compound-point of the measurement scale $(\mathrm{d}=0.2$ to 0.8$)$. The measurement scales were taken randomly in the related field and thus prevented partisanship. Points which corresponded to each cross-section were counted separately three times and the number of average points were found to be suitable for the brain and lateral ventricle (Fig. 1).

The cross-sectional area was calculated following the number of points. The volume was calculated by using a equipment for finding the value and slice thickness. The

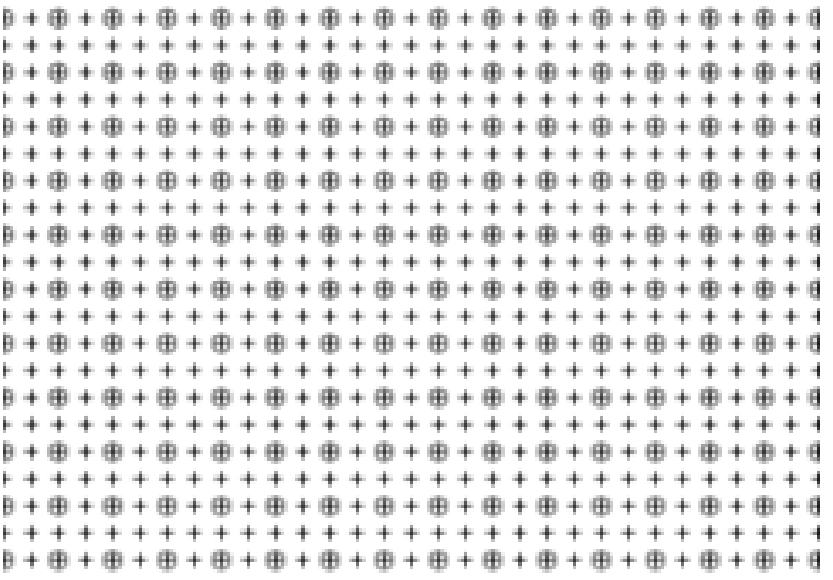

Fig. 1. Scale compound-point of the measurement scale

following formula was used for volume estimation $(14,16,17,18,19)$.

$$
\mathrm{V}=\mathrm{t} \times[((\mathrm{SU}) \times \mathrm{d}) / \mathrm{SL}] 2 \times \Sigma \mathrm{P}
$$

(V: volume, t: slice thickness, SU: length represents the scale which shows the magnification of image $d$ : the length between the two points of the compound-point of the measurement scale, SL: the length of the image scale as measured by $f$ the ruler or caliper, $\Sigma \mathrm{P}$ : number of the points corresponding to all sections )

After the point count values were completed, BV and LV data was entered into the appropriate places on the macro program that was prepared using Microsoft Excel. The findings of volume values were loaded onto the SPSS (ver: 14) program and were used to test which were analysis of variance, Kruskal-Wallies, test of Tukey, significance test of difference between two points for the evaluation. The tables of data reported the arithmetic mean $(\mathrm{x}) \pm$ standard deviation (S) with an error level of 0.05 .

\section{RESULTS}

According to sex in all ages (without dividing into age group) comparisons of BV,LV and RLBV\% are presented in Table I. The difference between girls and boys was insignificant for BV, LV and RLBV\% ( $>>0,05)$. The relationship between $\mathrm{BV}$ and $\mathrm{LV}$ were found in girls and boys $r=-0.029$ and $r=0.077$, respectively. This correlation was insignificant $(\mathrm{p}>0,05)$.

According to age groups comparisons of $\mathrm{BV}, \mathrm{LV}$ and RLBV\% without sex difference are shown in TableII. When $\mathrm{BV}$ was compared between age groups, the difference was 
Comparison of $\mathrm{BV}\left(\mathrm{cm}^{3}\right), \mathrm{LV}\left(\mathrm{cm}^{3}\right)$ and RLBV\% in all age groups.

\begin{tabular}{lccc}
\hline Sex & BV $\bar{X} \mathbf{~ S}$ & $\mathbf{L V} \bar{X} \mathbf{~ S}$ & RLBV \% $\bar{X} \mathbf{\pm S}$ \\
\hline Girl $(\mathrm{n}=50)$ & $1085,72 \pm 101,82$ & $10,76 \pm 3,09$ & $0,99 \pm 0,32$ \\
Boy $(\mathrm{n}=40)$ & $1112,20 \pm 134,46$ & $11,00 \pm 4,37$ & $0,94 \pm 0,40$ \\
& $\mathrm{p}=0,290$ & $\mathrm{p}=0,762$ & $\mathrm{p}=0,548$ \\
\hline
\end{tabular}

Table II. Comparison of BV, LV and RLBV\% between age groups

\begin{tabular}{|c|c|c|c|}
\hline Age groups & BV $\bar{X} \pm \mathbf{S}$ & $\mathbf{L V} \bar{X} \mathbf{\pm S}$ & $\operatorname{RLBV} \% \bar{X} \pm \mathrm{S}$ \\
\hline $6-9$ & $1019,43 \pm 115,01$ & $11,20 \pm 4,45$ & $1,04 \pm 0,46$ \\
\hline $10-13$ & $1154,20 \pm 92,70$ & $10.30 \pm 4,15$ & $0,89 \pm 0,36$ \\
\hline \multirow[t]{2}{*}{$14-17$} & $1118,83 \pm 102,22$ & $11,10 \pm 2,10$ & $0,98 \pm 0,19$ \\
\hline & $\mathrm{p}=0,000 \mathrm{p}<0,05$ & $\mathrm{p}=0,592$ & $\mathrm{p}=0,284$ \\
\hline
\end{tabular}

Table III. Comparison of BV,LV and RLBV\% values in girls for each age group.

\begin{tabular}{lccc}
\hline Age groups & $\mathbf{B V} \bar{X} \mathbf{~ S}$ & $\mathbf{L V} \bar{X}_{\mathbf{I S}}$ & $\mathbf{R L B V \%} \bar{X}_{\mathbf{A}}$ \\
\hline 6-9 (n:11) & $1012,42 \pm 121,66$ & $11,20 \pm 4,45$ & $1,04 \pm 0,46$ \\
$10-13$ (n:21) & $1123,50 \pm 94,39$ & $10.30 \pm 4,15$ & $0,89 \pm 0,36$ \\
$14-17$ (n:18) & $1100,05 \pm 66,50$ & $11,10 \pm 2,10$ & $0,98 \pm 0,19$ \\
& $\mathrm{p}=0,018$ & $\mathrm{p}=0,09$ & $\mathrm{p}=0,29$ \\
& $\mathrm{p}<0,05$ & $\mathrm{p}>0,05$ & $\mathrm{p}>0,05$ \\
\hline
\end{tabular}

Table IV. Comparison of BV,LV and RLBV\% values in boys for each age group.

\begin{tabular}{cccc}
\hline Ige groups & BV $\bar{X} \mathbf{~ S}$ & LV $\bar{X} \pm \mathbf{S}$ & RLBV\% $\bar{X} \mathbf{S}$ \\
\hline 6-9 (n:19) & $1024,76 \pm 113,16$ & $11,06 \pm 4,27$ & $0,96 \pm 0,42$ \\
$10-13$ (n:9) & $1200,25 \pm 70,93$ & $11,33 \pm 6,06$ & $0,95 \pm 0,52$ \\
$14-17$ (n:12) & $1151,27 \pm 143,23$ & $10,55 \pm 2,16$ & $0,91 \pm 0,19$ \\
& $\mathrm{p}=0,00$ & $\mathrm{p}=0,75$ & $\mathrm{p}=0,91$ \\
& $\mathrm{p}<0,05$ & $\mathrm{p}>0,05$ & $\mathrm{p}>0,05$ \\
\hline
\end{tabular}

Table V. Comparison of BV,LV and RLBV\% values according to sex difference for each age group.

\begin{tabular}{llcc}
$\begin{array}{l}\text { Age groups } \\
\text { (girls and }\end{array}$ & $\begin{array}{c}\text { BV } \bar{X} \mathbf{\pm S} \\
\text { (girls and boys) }\end{array}$ & $\begin{array}{c}\mathbf{L V} \bar{X}_{\mathbf{I S}} \\
\text { (girls and boys) }\end{array}$ & $\begin{array}{c}\text { RLBV\% } \\
\text { (girls and boys) }\end{array}$ \\
\hline $6-9$ & $1012,42 \pm 121,66$ & $11,20 \pm 4,45$ & $1,04 \pm 0,46$ \\
& $1024,76 \pm 113,16$ & $11,06 \pm 4,27$ & $0,96 \pm 0,42$ \\
$10-13$ & $1123,50 \pm 94,39$ & $10.30 \pm 4,15$ & $0,89 \pm 0,36$ \\
& $1200,25 \pm 70,93$ & $11,33 \pm 6,06$ & $0,95 \pm 0,52$ \\
$14-17$ & $1100,05 \pm 66,50$ & $11,10 \pm 2,10$ & $0,98 \pm 0,19$ \\
& $1151,27 \pm 143,23$ & $10,55 \pm 2,16$ & $0,91 \pm 0,19$ \\
$6-9$ & $\mathrm{p}=0,818 \mathrm{p}>0,05$ & $\mathrm{p}=0,850 \mathrm{p}>0,05$ & $\mathrm{p}=0,414 \mathrm{p}>0,05$ \\
$10-13$ & $\mathrm{p}=0,023 \mathrm{p}<0,05$ & $\mathrm{p}=0,639 \mathrm{p}>0,05$ & $\mathrm{p}=0,799 \mathrm{p}>0,05$ \\
$14-17$ & $\mathrm{p}=0,077 \mathrm{p}>0,05$ & $\mathrm{p}=0,183 \mathrm{p}>0,05$ & $\mathrm{p}=0,093 \mathrm{p}>0,05$ \\
\hline
\end{tabular}

found significant $(\mathrm{p}<0,05)$. The BV of children that 6-9 age group was significantly smaller than other groups. The relationship between BV and LV were found into three age groups of 6-9, 10-13 and 14-17, $r=-0.049, r=0.098$ and $\mathrm{r}=0,198$ respectively.
According to age groups comparisons of $\mathrm{BV}, \mathrm{LV}$ and RLBV\% in girls are given in the Table III. When BV of girls for each age group were compared among themselves, results was found significant between 6-9 age group and other groups. When RLBV\% of girls for each age group were compared among themselves, results was found significant between 6-9 age group and 10-13 age group. But the comparison of LV for girls among themselves was insignificant.

According to age groups comparisons of $\mathrm{BV}, \mathrm{LV}$ and RLBV\% in boys are given in the Table 4 . When BV of boys for each age group were compared among themselves, results was found significant between 6-9 age group and other groups. But the comparison of LV and RLBV\% for boys among themselves was insignificant.The comparison of $\mathrm{BV}, \mathrm{LV}$ and RLBV\% values according to sex in same age groups, BV was found significant between girls and boys in 1013 age group while LV and RLBV\% values was found insignificant.

According to sex difference in age groups comparisons of $\mathrm{BV}, \mathrm{LV}$ and RLBV\% are given in the Table 5. When $\mathrm{BV}$ for each age group were compared between girls and boys, results was found significant in 10-13 age group although LV and RLBV\% was insignificant in all groups.

\section{DISCUSSION}

Although the development of the brain is more active in the intrauterine period of life, brain structure is affected by many other processes such as myelination and arborization throughout childhood and adolescence (Giedd, 1999). The development process of the human brain continues for approximately 15 years; including the period of pregnancy. The growth rate is very fast during the intrauterine period and the first few 
months after birth (3). The total intracranial volume and the volume of different cerebral parts increase rapidly in the first two years of a child's life and this change continues, but more slowly, up to adolescents. In a variety of studies related to this field of investigation there is conflicting findings. For example, according to Caviness et al., 1996, Giedd, 1999 and Lenroot et al., 2006, 95\% of brain volume is completed at 9 years, 5 years and 6 years, respectively. In spite of myelination of white matter generally increases with age, gray matter decreases. Corpus callosum, which contains most white matter in the brain, increases $1.8 \%$ between 3-18 years in each year. While the number of cells which is cited at front of brain and brain stem increase, water volume decreases until the age of eight from pre-natal development (Zhang et al, .2005). The findings from studies in the literature on $\mathrm{BV}$ are presented in TableVI.

When BV values of this study were compared with other studies, results were generally similar. Our values were found to be close with the values of Reiss et al., 1996, Lange et al., 1997 and Giedd et al., 1999 but were found to be lower than the values of Bellis et al., 2001. This study revealed that brain volume was greater in boys than girls between 6-17 years and age groups $(6-9,10-13,14-17)$. It is not entirely clear how sex factors affect the changes in the brain with the increasing of age, but it is thought that both internal and external factors influence these volume changes. For example, sex hormones play a significant role in terms of changes in the brain as the level of sex hormones remains relatively constant in organisms. Also, the volumetric changes of the brain may be affected by environmental conditions, nutrition and genetic factors. In addition, height and weight are known to affect the volume of the brain which is thought to explain the change in brain volume of boys and girls (Xu et al., 2000; Manjunath et al., 2002). However, it is not known whether the differences in total brain size constitute a functional advantage or not. Different functions such as large structural measurements, neural relationships and receptor sensitivity cannot be related to sexually dimorphic differences (Lenroot et al., 2006).

The studies performed after the ages of 16-17 demonstrated that brain volume is greater in boys than in girls. However, it also demonstrated that the loss of $\mathrm{BV}$ is greater in boys than in girls (Courchesne et al., 2000).
The morphometric measurements of LVV are more variable because lateral ventricles share a common border with other brain structures (Thune et al., 2000; Wang et al., 2002; Giedd et al., 2010). LVV can change more or less because of an abnormality in any area of the brain. The changes of the forebrain structures such as the hypothalamus, thalamus, limbic system and basal ganglia is affected by lateral ventricles.Cortical and especially subcortical atrophy is associated with ventricular enlargement. Many studies related with this matter show that an increase of LVV results in a decrease in BV (Courchesne et al., 2000; Wang et al., 2002). However, it is not possible to know to what extent the reduction in any area of the brain tissue is caused by ventricular enlargement (Creasey et al., 1986; Wang et al., 2002).

Lange et al. (1997) reported a mean value of LVV 10, 08 among healthy children according to age and sex. This value was expressed as 9.28 for boys and 10.68 for girls. Giedd et al., 1996, reported that LVV increased with age and this was more significant in boys. Reiss et al., 1996, reported value of LVV $11.9 \pm 5.7$ for boys and $15.5 \pm 9.5$ for girls (29). Our study demonstrated that the relationship between $\mathrm{LVV}$ and $\mathrm{BV}$ is positive for boys but negative for girls with age. Also, the numerical results of our study were found to be compatible with other pediatric studies. Compared with findings from other studies, the mean LVV estimated was greater in boys than in girls in all age groups and the result is consistent with the study of Giedd et al., (1996). Moreover, values of LVV in our study was found to be more than Lange et al., (1997), but less than Reiss et al., (1996).

It is stated in the literature that there is a correlation between the BLVVR and the LVV changes. The studies related to BLVVR by Giedd et al., demonstrated that the increase in BLVVR is in correlation with the increase in LVV and minimal changes occurred with the changes of the ventricular volume (Giedd et al., 1996). In studies related to LVV changing by age changing. Barron et al., (1976) emphasized that LVV increased with age. For instance, they reported BLVVR as $1.8 \pm 0.4 \%$ between $0-9$ years and as $3.3 \% \pm 0.7$ between $10-19$ years.

When the values of our study were compared between age groups, it was found that LVV was decreased between 10-13 years and was increased between 14-17 years. But

Table VI. The litterateur of BV changes according to age and sex $\left(\mathrm{BV} ; \mathrm{cm}^{3}\right)$

\begin{tabular}{lcccc}
\hline Authors & Age groups & Subjects & Girls (BV) & Boys (BV) \\
\hline Giedd et al. $(2)$ & $4-18$ & 104 & BV is great in boys more than girls \\
Giedd et al. $(28)$ & $4-22$ & 145 & 1260 & 1382 \\
Lange et al. $(10)$ & $4-20$ & 115 & 1072,82 & 1169,63 \\
Reiss et al. $(29)$ & $5-17$ & 85 & $1182,5 \pm 104,7$ & $1290,6 \pm 147,4$ \\
Bellis et al. (30) & $6-17$ & 118 & $1188,5 \pm 85,7$ & $1344,53 \pm 123,41$ \\
\hline
\end{tabular}


BLVVR was decreased between 10-13 years and was increased between 14-17 years.

Our study can provide very important data for neuroanatomical development. The aim of our study is to create a model in a group which includes healthy children between the ages of 6-17 and to show the brain and lateral ventricle volume change and produce their relationship with age and sex. Fundamental changes in the brain between these age groups can be a reflector or predictor for the normal development of behavioral patterns. Changes in brain structures are important indicator of many psychiatric disorders. However, most childhood neuropsychiatric disorders are diagnosed in children between the age group of 4-18. Thus, the normal values which were found in this study can be an extremely important guide for further research.

KARACAN, K.; KOSAR, M. I.; ÇIMEN, M.; SOLAK, O. \& SAHIN, B. Determinación del volumen del ventrículo lateral y del cerebro en niños utilizando el método estereológico mediante MRI. Int. J. Morphol., 31(1):211-216, 2013.

RESUMEN: Aunque el desarrollo del cerebro es más activo durante el período de la vida intrauterina, los procesos de mielinización y arborización afectan a la estructura del cerebro durante la infancia y la adolescencia. El desarrollo del cerebro es activo en los primeros años de la vida, y sigue siendo así durante unos 15 años después de la gestación. Cambios volumétricos en el cerebro son afectados según el sexo. La comprensión de la variabilidad del volumen del cerebro humano durante el desarrollo es importante para la interpretación de los estudios de neuroimagen en la infancia. Por lo tanto, el objetivo de este estudio fue determinar, a través de resonancia nuclear magnética, los efectos de las diferencias de sexo en el volumen cerebral (VC), en el volumen del ventrículo lateral (VL) y la relación porcentual de los volúmenes del cerebro y del ventrículo lateral (\% VLVC) de 90 niños sanos entre 6-17 años de edad, en ambos sexos. Los niños fueron divididos en tres grupos de edad: 6-9, 10-13 y 14-17. El VC y el VL se calcularon utilizando el principio de Cavalieri, además de la relación porcentual RLBV. El VC del grupo 6-9 años fue significativamente menor que el de los otros dos grupos (p <0,05). El promedio del BC del grupo 10-13 años fue superior a los otros dos grupos de edad, pero esta diferencia fue mínima. Cuando se compararon los grupos en cuanto al sexo, no hubo diferencia entre niños y niñas ( $\mathrm{P}>0,05)$. El promedio general del grupo VL de 6-9 años fue mayor que los otros dos, sin diferencia significativa entre ambos sexos. El VC siguió aumentando hasta los 10-13 años en ambos sexos. Mientras LV aumentó hasta los 10-13 años de edad en los niños, se observó en las niñas una relación negativa con cambios de BV.

PALABRAS CLAVE: Cerebro; Ventrículos laterales; Imágenes por resonancia magnética; Estereología

\section{REFERENCES}

Barron, S.; Jacobs, L. \& Kinkel, W. Changes in size of normal lateral ventricles during aging determined by computerized tomography. Neurology, 26(11):1011-3, 1976.

Castellanos, F. X.; Lee, P. P.; Sharp, W:, Jeffries, N. O.; Greenstein, D. K.; Clasen, L. S.; Blumenthal, J. D.; James, R. S.; Ebens, C. L.; Walter, J. M.; Zijdenbos, A.; Evans, A. C.; Giedd, J. N.; Rapoport, J. L. Developmental Trajectories of Brain Volume Abnormalities in Children and Adolescents With AttentionDeficit/Hyperactivity Disorder. JAMA, 288(14):1740-8, 2002.

Caviness, V. S.; Kennedy, D. N.; Richelme, C.; Rademacher, J.; Filipek, P. A. The Human Brain Age 7-11 Years: A Volumetric Analysis Based on Magnetic Resonance Images. Cerebral Cortex, 6(5):726-36, 1996.

Courchesne, E.; Chisum, H. J.; Townsend, J.; Cowles, A.; Covington, J.; Egaas, B.; Harwood, M.; Hinds, S. \& Press, G. Normal brain development and aging: Quantitative analysis at in vivo MR imaging in healthy volunteers. Neuroradiology, 216(3):672-82, 2000

Creasey, H.; Rumsey, J. M.; Schwartz, M.; Duara, R.; Rapoport, J. L.; Rapoport, S. I. Brain morphometry in autistic men as measured by volumetric comut. Arch. Neurol. 43(7):669-72, 1986.

De Bellis, M. D.; Keshavan, M. S.; Beers, S. R.; Hall, J.; Frustaci, K.; Masalehdan, A.; Noll, J. \& Boring, A. M. Sex Differences in Brain Maturation during Childhood and Adolescence. $\mathrm{Ce}$ rebral Cortex, 11(6):552-7, 2001.

Giedd, J.; Snell, J. W.; Lange, N.; Rajapakse, J. C.; Casey, B. J.; Kozuch, P. L.; Vaituzis, A. C.; Vauss, Y. C.; Hamburger, S. D.; Kaysen, D. \& Rapoport, J. L. Quantitative magnetic resonance imaging of human brain development: ages 4-18. Cereb. Cortex., 6(4):551-60, 1996.

Giedd, J. N.; Blumenthal, J.; Jeffries, N. O.; Castellanos.; F. X.; Liu, H.; Zijdenbos, A.; Paus, T.; Evans, A. C. \& Rapoport, J. L. Brain development during childhood and adolescence: A longitudinal MRI study. Nature Neuroscience, 2(10):861-3, 1999.

Giedd, J. N. Brain development: IX. Human brain growth. Am. J. Psychiatry, 156(1):4, 1999.

Giedd, J. N.; Stockman, M.; Weddle, C.; Liverpool, M.; Alexander- 
Bloch, A.; Wallace, G. L.; Lee, N. R.; Lalonde, F.; Lenroot, R. $\mathrm{K}$. Anatomic magnetic resonance imaging of the developing child and adolescent brain and effects of genetic variation. Neuropsychol Rev., 20(4):349-61, 2010.

Gooding, C. A.; Brasch, R. C.; Lallemand, D. P. Wesbey, G.E. \& Brant-Zawadzki, M. N. Nuclear magnetic resonance imaging of the brain in children. J. Pediatr., 104(4):509-15, 1984.

Gundersen. H. J.; Jensen, E. B.; Kiêu, K. \& Nielsen, J. The efficiency of systematic sampling in stereology-reconsidered. J. Microsc., 193(3):199-211, 1999.

Hansen, P. E.; Ballesteros, M. C.; Soila, K.; García, L. \& Howard, J. M. MR Imaging of the developing human Brain. Parte 1. Prenatal Development. RadioGraphics, 13:21-36, 1993.

Kesler, S. R.; Ment, L. R.; Vohr, B.; Pajot, S. K.; Schneider, K. C.; Katz, K. H.; Ebbitt, T. B.; Duncan, C. C.; Makuch, R. W. \& Reiss, A. L. Volumetric analysis of regional cerebral development in preterm children. Pediatr. Neurol., 31(5):31825, 2004.

Lange, N.; Giedd, J. N.; Castellanos, F. X.; Vaituzis, A. C. \& Rapopor, J. L. Variability of human brain structure size: ages 4-20 years. Psychiatry Reserch: Neuroimaging, 74(1):1-12, 1997.

Lawson, J. A.; Vogrin, S.; Bleasel, A. F.; Cook, M. J. \& Bye; A. M. Cerebral and cerebellar volume reduction in children with intractable epilepsy. Epilepsia, 41(11):1456-62, 2000.

Lenroot, R. S. \& Giedd, J. N. Brain develoment in child and adolescents: Insights from anatomical magnetic resonance Imaging. Neuroscience and Biobehavioral Review, 30:718-29, 2006.

Reiss, A. L.; Abrams, M. T.; Singer, H. S.; Ross, J. L. \& Denckla, M. B. Brain development, gender and IQ in children: A volumetric imaging study. Brain J. Neurology, 119(5):176374, 1996.

Sowell, E. R.; Peterson, B. S.; Kan, E.; Woods, R. P.; Yoshii, J.; Bansal, R.; Xu, D.; Zhu, H.; Thompson, P. M. \& Togal, A. W. Sex Differences in Cortical Thickness Mapped in 176 Healthy Individuals between 7 and 87 Years of Age. Cerebral Cortex, 17(7):1550-60, 2007.

Steen, R. G.; Ogg, R. J.; Reddick, W. E. \& Kingsley, P. B. Agerelated changes in the pediatric brain: quantitative MR evidence of maturational changes during adolescence. AJNR Am. J. Neuroradiol., 18:819-28, 1997.

Thune, J. J. \& Pakkenberg, B. Stereological studies of the schizophrenic brain. Brain Research Reviews, 31(2-3):200-4, 2000.

Wang, D.; Chalk, J. B.; Rose, S. E.; de Zubicaray, G.; Cowin, G.;
Galloway, G. J.; Barnes, D.; Spooner, D.; Doddrell, D. M. \& Semple, J. MR image-based measurement of rates of change in volumes of brain structures. Part II: application to a study of Alzheimer's disease and normal aging. Magnetic Resonance Imaging, 20(1):41-8, 2002.

Wang, D. \& Doddrell, D. M. MR image-based measurement of rates of change in volumes of brain structures. Part I: method and validation. Magnetic Resonance Imaging, 20(1):27-40, 2002.

Xu, J.; Kobayashia, S.; Yamaguchia, S.; Iijimaa, K.; Okadaa, K. \& Yamashitaa, K. Gender Effects on Age-Related Changes in Brain Structure. Am. J. Neuroradiol., 21(1):112-8, 2000.

Zhanga, L.; Thomasb, K. M.; Davidsonb, M. C.; Caseyb, B. J.; Heiera, L. A. \& Ulug a, A. M. MR Quantitation of Volume and Diffusion Changes in the Developing Brain. Am. J. Neuroradiol., 26(2):45-9, 2005.

\section{Correspondence to: \\ Keziban KKaracan \\ Department of Anatomy \\ Cumhuriyet University \\ Faculty of Medicine \\ 58140 Sivas \\ TURKEY}

E-mail:keziban_kalkan@hotmail.com

Received: 16-05-2012

Accepted: 10-12-2012 